\title{
Aerosol Optical Depth Pathways and Sources; Lake Victoria Basin*
}

\author{
Misiani Zachary ${ }^{1,2 \#, ~ L u n ~ Y i n}{ }^{3}$, Mwai Zacharia ${ }^{1,2}$ \\ ${ }^{1}$ School of Atmospheric Sciences, Nanjing University of Information Science and Technology, Nanjing, China \\ ${ }^{2}$ Kenya Meteorological Department, Ministry of Environment \& Natural Resources, Nairobi, Kenya \\ ${ }^{3}$ Yunnan Academy of Social Sciences, Kunming, China \\ Email: ${ }^{*}$ zacharymisiani@gmail.com
}

How to cite this paper: Zachary, M., Yin, L. and Zacharia, M. (2018) Aerosol Optical Depth Pathways and Sources; Lake Victoria Basin. Open Access Library Journal, 5: e4393.

https://doi.org/10.4236/oalib.1104393

Received: February 1, 2018

Accepted: March 3, 2018

Published: March 6, 2018

Copyright ( $\odot 2018$ by authors and Open Access Library Inc.

This work is licensed under the Creative Commons Attribution International License (CC BY 4.0).

http://creativecommons.org/licenses/by/4.0/

\begin{abstract}
The air mass back-trajectory clustering analysis was combined with Aerosol Optical Depth (AOD) of fine mode, coarse mode and fine mode fraction in order to evaluate the long-range effects of transportation patterns of trajectories for the ground based station at ICIPE Mbita which is located on longitude and latitude of $34.2^{\circ} \mathrm{E}, 0.417^{\circ} \mathrm{S}$ respectively at 1125 meters above sea level. In order to get a clear picture of the source and sinking points of aerosols, monthly means of a 72 hour backward trajectories data ranging from 2013 to 2015 were used in categorizing the cluster into five classes. Most of the air trajectories analysis from this paper shows evidence that the major sources and pathways for the aerosols into the receptor station commonly originate from as far as the Arabian deserts and Sahara deserts from the Northern Hemisphere and Indian Ocean and central Africa in the Southern Hemisphere.
\end{abstract}

\section{Subject Areas}

Atmospheric Sciences, Environmental Sciences

\section{Keywords}

Aerosols, Cluster Analysis, MAM, JJA, Trajectories, ICIPE Mbita and AERONET, LBR

\section{Introduction}

Atmospheric aerosol is the suspension of liquid and solid particles with varying diameter mostly smaller than 1 micrometer $(\mu \mathrm{m})$ to larger than 100 micrometer

*This is a common cluster method and approach of studying how atmospheric aerosols are transported from different sources to specific receptor site. 
$(\mu \mathrm{m})$ in the atmosphere that plays an important role in solar radiation budget, climate change, hydrological process, air quality and visibility through the effect of scattering, reflection and absorption of incoming solar energy from the sun [1].

Lake Victoria Basin Region of Kenya which is accustomed by the complex interactions of climatic and topographic effects of the atmospheric dynamics has a diverse physical features ranging from the hills of the Northern Bungoma County to the lower plains bordering Lake Victoria which is the largest and fresh water lake in Africa. The sources of this Fine Mode AOD, Coarse Mode AOD, and Fine Mode Fraction concentration aerosol vary significantly from place to place and time of year. The land/lake-breezes cycle defines local winds and influence the transportation of particles from/to neighboring areas. The combination of low wind speeds and land/lake-breezes leads to a higher concentration of aerosol particles.

From early as 1940s since its development, the back trajectory analysis has been utilized as one of the most powerful tool for tracking the spatial domain of air parcels arriving at receptor sites tracking the history and pathway of air parcels and pollutants [2].

This study aims at investigating the transport pathways and potential sources of Fine Mode, Coarse Mode, and Fine Mode Fraction AOD based on backward trajectories and AOD concentration records in 2013, 2014 and 2015 at ICIPE Mbita AERONET station at $34.2^{\circ} \mathrm{E},-0.417^{\circ} \mathrm{S}$, and 1125 meters above sea level next to Kisumu city. The results from this research would not only provide some scientific basis for improving the air quality in this region especially in Kisumu city and the ecological environment of the surrounding regions, but also accumulate some experience for cities with similar situation in the world.

\section{Material and Methods}

\subsection{Data for the Study}

Data used in this study is from two sources as described below:

The Fine Mode, Coarse Mode Aerosol Optical Depth (AOD), and Fine Mode Fraction AOD concentrations for ICIPE Mbita in wet and dry seasons from 2013 to 2015 were downloaded from AERONET Aerosol Robotic Network for level 2.0 daily averages, available at https://aeronet.gsfc.nasa.gov/new_web/index.html.

In this study, a 72 -hour back-trajectories arriving at $1,125 \mathrm{~m}$ above ground level were calculated for every 6 hours $(00,06,12,18$ UTC) a day, from March to August for 2013 to 2015 using the National Oceanic and Atmospheric Administration (NOAA) HYSPLIT4 trajectory model [3] and [4] available at http://www.arl.noaa.gov/ready/hysplit4.html).

The National Centers for Environmental Prediction, Final Analyses (NCEP/FNL) archive data downloaded from NOAA were used as meteorological data input to the model. The final model outputs were hourly trajectory end- 
points indicating the geographical location and the height of the air parcel.

\subsection{Area of Study}

The Lake Victoria Basin Region (LVBR) is one of the most densely populated regions of Kenya with over 10 million people which constitutes about $25 \%$ of the population in Kenya [5]. The study site is located at ICIPE Mbita AERONET ground station at Longitude $34.2^{\circ} \mathrm{E}$, and Latitude $-0.42^{\circ} \mathrm{S}, 1125$ meters above sea level, marked with a red dot in the map, in Kisumu city, Longitude $0.0917^{\circ} \mathrm{S}$, $34.7680^{\circ} \mathrm{E}$ and 1131 meters above sea level, marked black in color which is largest city in this region next to Lake Victoria Figure 1. The counties that constitute the Lake Region are Kakamega, Kisii, Kisumu, Bungoma, Busia, Homa Bay, Migori, Siaya, Vihiga and Nyamira [6]. Rainfall is seasonal throughout this region with the highlands of western Kenya having one rainy season (unimodal) that spans from March to September while the Lake Basin have two rainy seasons(bimodal) with the short rains coming from October to December (OND) and the long rains extending from March to May (MAM) [7]. The warmest period ranges from February to March, originally dry winds originating from Arabia prevail, while the coolest period ranges from July to August (JJA) with the prevailing winds originating from the Indian Ocean, although the seasonal variations in temperature are minimal. Both temperature and rainfall varies according to the prevailing winds. The rains occur mainly in the form of downpour or thunderstorm in the afternoon or evening, and are pretty irregu$\operatorname{lar}[8]$.

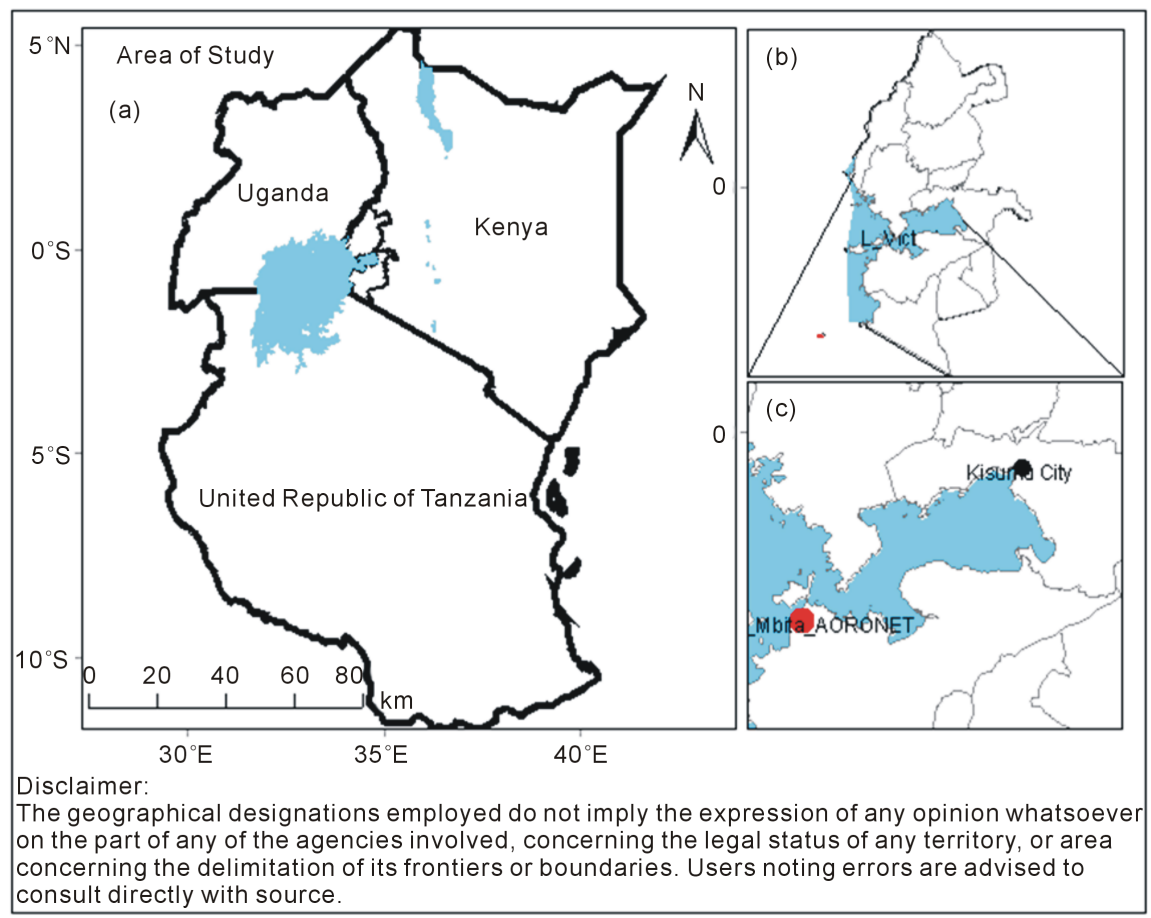

Figure 1. Geographical location of ICIPE Mbita AERONET ground station (red dot) and Kisumu city (black dot). This Map was produced on $5^{\text {th }}$ December 2017 by Misiani Zachary. 


\section{Results and Discussion}

\subsection{Fine Mode, Coarse Mode Aerosol Optical Depth (AOD) and Fine Mode Fraction Aerosol Optical Depth in Wet and Dry Seasons}

Daily and seasonal mean of Fine Mode AOD, Coarse Mode AOD, and Fine Mode Fraction concentrations from $1^{\text {st }}$ March 2013 to $31^{\text {st }}$ May 2015 and $1^{\text {st }}$ June 2013 to $31^{\text {st }}$ August 2015 are generated and represented in time series analysis in Figure 2. In all the seasons the results are represented in Figure 3 below, there is a feeble decrease in trend for both MAM and JJA for all the Fine Mode AOD, Coarse Mode AOD, and Fine Mode Fraction concentration. From the MAM time series graph, evidence showed that during this wet period there is a large decrease of all the AOD especially in the month of April which is the peak of the long rain period in Kenya.

This can be attributed that during rainy period, precipitation could have washed away most of the aerosol loadings hence lowering its concentration in the atmosphere, a process commonly known as scavenging, in addition to that,
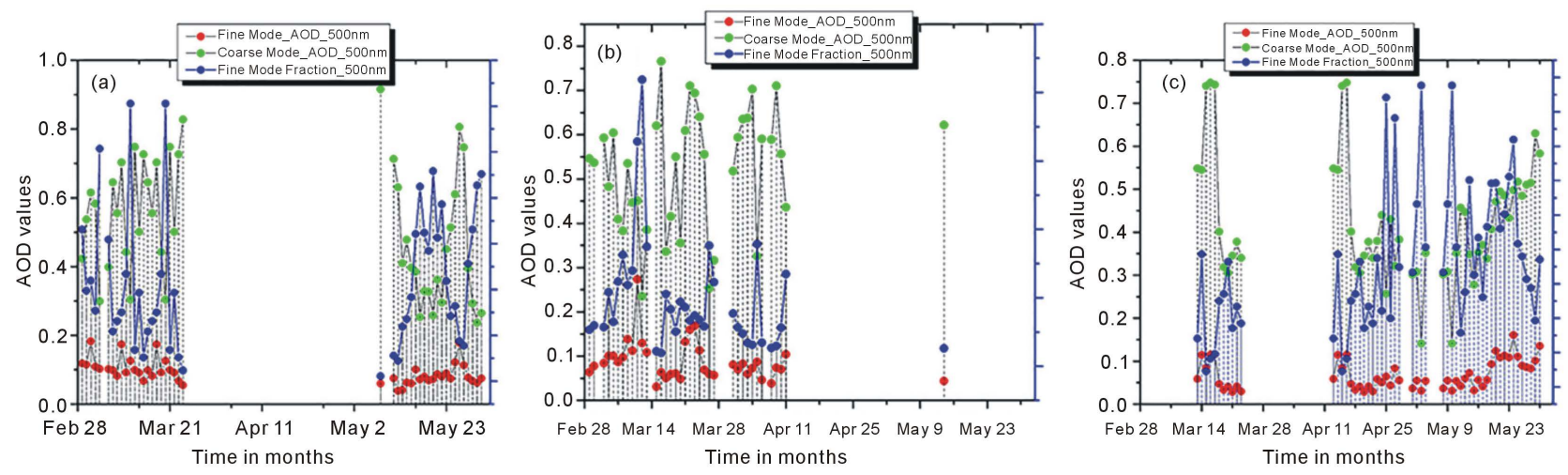

Figure 2. Fine Mode AOD, Coarse Mode AOD, and Fine Mode Fraction AOD concentrations at ICIPE Mbita during wet season (MAM) for 2013, 2014 and 2015 (a), (b) and (c) respectively. The red dots indicate fine mode, green dots indicates coarse mode while blue dots indicate fine mode fraction AOD values.
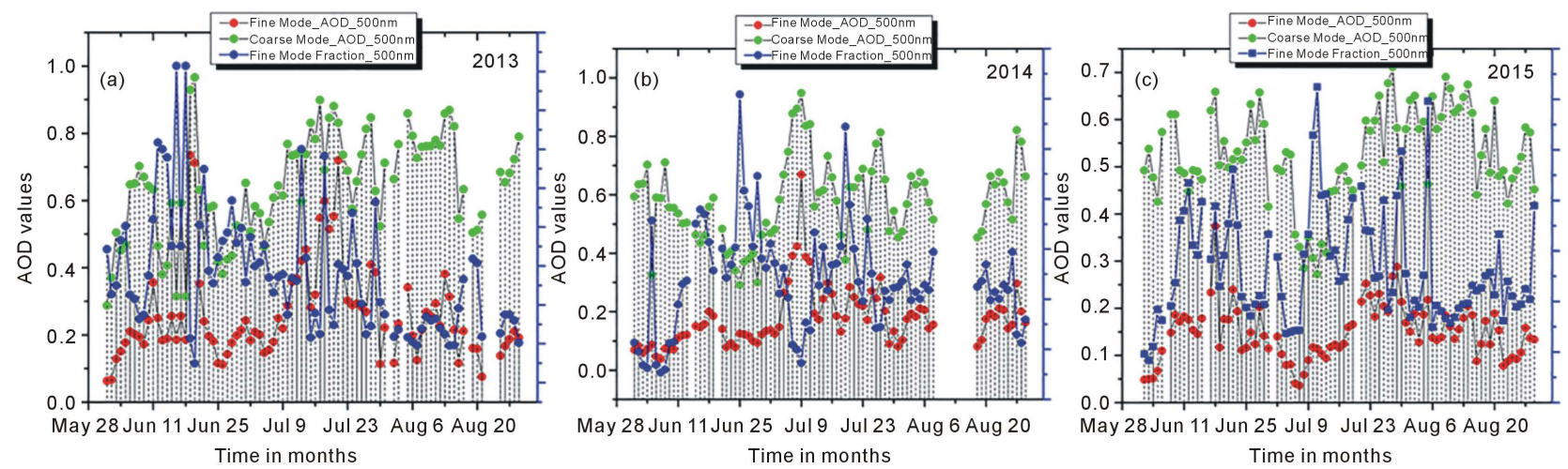

Figure 3. Fine Mode AOD, Coarse Mode AOD, and Fine Mode Fraction AOD concentrations at ICIPE Mbita during dry season (JJA) for 2013, 2014 and 2015 (a), (b) and (c) respectively. The red dots indicate fine mode, green dots indicates coarse mode while blue dots indicates fine mode fraction AOD values. 
this period also enhances the growth of the vegetation which could also prevent dust emission through increasing the soil moisture by suppressing wind-induced dust emissions from the ground.

However, during dry periods the residue varies freely due to aerosol emissions from arid areas and sea salt. This compounded with reduced scavenging leads to high AOD values over the study area. The maximum concentration occurs during the month of July.

\subsection{Transport Pathways of AOD Contributions}

In order to analyze the association between trajectories and fine mode AOD, coarse mode AOD, and fine mode fraction concentration in air arriving at the ICIPE Mbita site, air mass backward trajectory cluster analysis was used to classify trajectories into clusters of similar history, that is, similar path to advection and velocity of air flow, meaning that the errors in the individual trajectories tend to average out.

The 72 hours backward trajectories ending from ICIPE Mbita AERONET station $\left(0.41^{\circ} \mathrm{S} 34.19^{\circ} \mathrm{E} 1125\right.$ meter above sea level) for MAM, 2013 - 2015 is represented below Figure 4(a), Figure 4(b) and Figure 4(c). The data set of geographical coordinates of air parcel backward trajectories, having reached the ICIPE Mbita site, was calculated at every 6 hour intervals for a period between 0 to 96 hours before arrival.
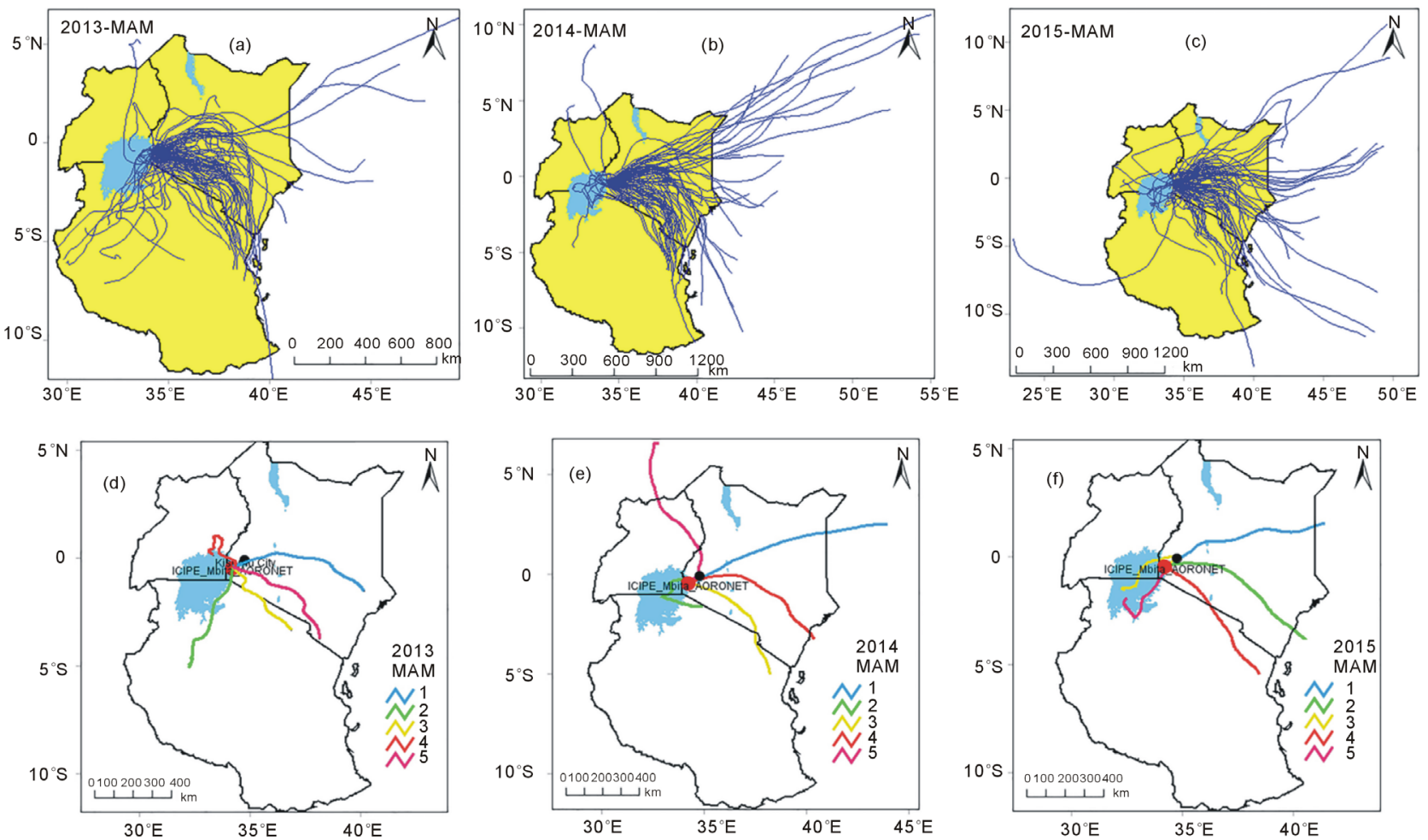

Figure 4. 72 hours backward trajectories ending from ICIPE Mbita AERONET station for MAM 2013, 2014 and 2015 for Figure 4(a), Figure 4(b) and Figure 4(c) while Figure 4(d), Figure 4(e) and Figure 4(f) show the cluster-mean back-trajectories (1 - 5) of ICIPE Mbita in MAM for 2013, 2014 and 2015 respectively. 

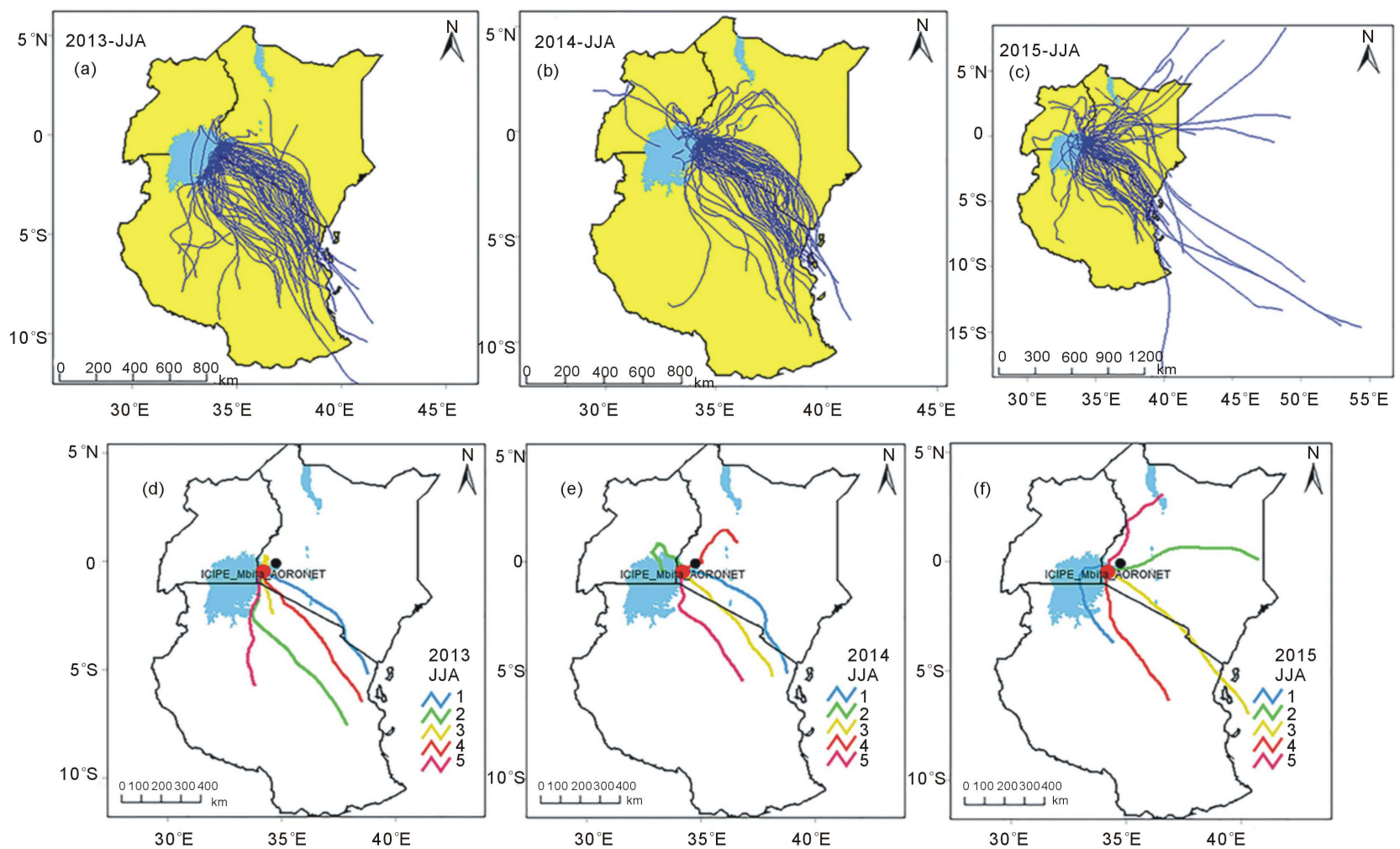

Figure 5. 72 hours backward trajectories ending from ICIPE Mbita AERONET station for JJA for 2013, 2014 and 2015 for Figure 5(a), Figure 5(b) and Figure 5(c) while Figure 5(d), Figure 5(e) and Figure 5(f) show the Cluster-mean back-trajectories (1 - 5) of ICIPE Mbita in JJA for 2013, 2014 and 2015 (a), (b) and (c) respectively.

During MAM season, air mass carrying the aerosols comes from Madagascar Island, far from Arabian Peninsula, and the southwestern Indian Ocean Figure 5(a), Figure 5(b) and Figure 5(c). However, due to enhanced rainfall during this wet season, the wet scavenging process could have been one of the main reasons why there was a decrease in AOD loading.

During JJA air masses originated from southwest Indian Ocean, Democratic Republic of Congo (DRC), South Atlantic Ocean, and as far as the Arabian Peninsula and with some locally produced aerosols. Those from the DRC and Madagascar Island and the locally produced pollutants traveled shorter distances hence spending more time over land leading to the contribution of most of the enhanced loadings during this dry period of the year.

These findings are consistent with previous experimental work carried out by [9] who observed that the main sources of aerosols over Mount Kenya in East Africa were locally derived and transported from central parts of Africa, and the Indian Ocean. On the same note, [10] [11] Observed that dust and sea salt aerosols were transported to Kenya from Arabian Peninsula and the southwest Indian Ocean.

From Figure 4(a), Figure 4(b) and Figure 4(c) it can be seen that most of the trajectories are originating from the northern hemisphere with north easterlies dominating. During the wet season, the North East (NE) monsoon winds are 
more prominent in Kenya. As the season changes to dry period of JJA as shown in Figure 5(a), Figure 5(b) and Figure 5(c), the winds also changes and become south easterlies originating from the Indian Ocean and Madagascar Island. Due to the change of wind direction, the concentration of aerosols also vary with time because of wind trajectories passing over different regions with different land scape such as arid and semi-arid regions.

\subsection{Cluster-Mean Backward Trajectories}

Five clusters were produced by the clustering algorithm for the MAM and JJA 2013, 2014 and 2015 years, and the cluster-mean trajectories. The transport routes and the direction of trajectories indicate the geographical areas traveled by air masses before their arrival at the receptor site. The length of the cluster-mean trajectories indicates the transport speed of air masses. The longer the cluster-mean trajectory, the faster the air mass.

It was observed that the eastern and south eastern path for cluster 1 and cluster 5 Figure 4(d), Figure 4(e) and Figure 4(f)) had longer trajectories than from other directions during MAM season for the years 2013, 2014 and 2015, indicating that air masses from the east and southeast moved faster than others. The air mass associated with cluster 1 passed through arid and semiarid areas of Garissa, Tana River and Kitui then Meru, Laikipia, Baringo, Nandi and finally through Kisumu while for cluster 5 were from Taita Taveta, Makueni, Machakos, Kajiado, Narok, Bomet, Nyamira and finally Kisumu as it converged at ICIPE Mbita.

During the JJA season from Figure 5(d) Figure 5(e) and Figure 5(f)) the air mass associated with all the 5 clusters were from southeast of Kenya and northeast parts of Tanzania with cluster 1 being the longest followed by cluster 2 and 4 respectively. The air masses associated with cluster 1 moved from Tanga and Kilimanjaro bordering Tanzania and Kenya into Taita Taveta, Kajiado, Narok and finally to receptor site. The air masses associated with clusters 2 and 4 initially followed parallel paths of southeastern Tanzania. Subsequently, the cluster 2 air masses passed over the Morogoro, Dodoma, and Shinyanga and they finally turn south through Mara to ICIPE Mbita. Cluster 4 air flowed over the Pwani, Tanga, Manyara, and Arusha finally through Mare bordering Tanzania and Kenya on the way to ICIPE Mbita. In comparison, the pathways represented by clusters 2 and 4 for MAM season and clusters 3 and 5 for JJA season Figure 4(d) and Figure 5(d) were considered less important source contributors of transport pollutants during 2013.

The number of trajectories in each cluster and the corresponding AOD mean concentrations for all trajectories are summarized in Table 1 to Table 6. The standard deviation, and mean values from the above tables were automatically generated through running the model in Meteoinfo Cluster Statistics after the field, cluster number, pollution criterion and missing value were set thereafter the statistical result were shown with their corresponding trajectory numbers, 
Table 1. Trajectory number and Fine Mode AOD, Coarse Mode AOD \& Fine Mode Fraction mean concentration of each cluster of ICIPE Mbita, in MAM 2013.

\begin{tabular}{cccccccc}
\hline & & \multicolumn{3}{c}{ Trajectory Number for wet season } \\
\cline { 3 - 8 } Trajectory Number & \multicolumn{2}{c}{ Fine Mode } & \multicolumn{2}{c}{ Coarse Mode } & \multicolumn{2}{c}{$\begin{array}{c}\text { Fine Mode } \\
\text { Fraction }\end{array}$} \\
\hline Cluster & Number & Mean & S.D & Mean & S.D & Mean & S.D \\
1 & 19 & 0.13 & 0.03 & 0.13 & 0.07 & 0.63 & 0.11 \\
2 & 3 & 0.11 & 0.02 & 0.19 & 0.1 & 0.00 & 0.00 \\
3 & 5 & 0.11 & 0.01 & 0.15 & 0.1 & 0.67 & 0.07 \\
4 & 2 & 0.00 & 0.00 & 0.12 & 0.00 & 0.75 & 0.00 \\
5 & 12 & 0.16 & 0.04 & 0.13 & 0.06 & 0.69 & 0.10 \\
\hline
\end{tabular}

Table 2. Trajectory number and Fine Mode AOD, Coarse Mode AOD \& Fine Mode Fractions mean concentration of each cluster of ICIPE Mbita, in JJA 2013.

\begin{tabular}{cccccccc}
\hline & & \multicolumn{3}{c}{ Trajectory Number for wet season } \\
\cline { 3 - 8 } Trajectory Number & \multicolumn{2}{c}{ Fine Mode } & \multicolumn{2}{c}{ Coarse Mode } & \multicolumn{2}{c}{$\begin{array}{c}\text { Fine Mode } \\
\text { Fraction }\end{array}$} \\
\cline { 3 - 9 } & & Mean & S.D & Mean & S.D & Mean & S.D \\
\hline 1 & 23 & 0.26 & 0.05 & 0.14 & 0.06 & 0.64 & 0.1 \\
2 & 19 & 0.35 & 0.14 & 0.15 & 0.09 & 0.72 & 0.09 \\
3 & 6 & 0.22 & 0.01 & 0.07 & 0.02 & 0.74 & 0.1 \\
4 & 17 & 0.38 & 0.21 & 0.16 & 0.08 & 0.71 & 0.14 \\
5 & 11 & 0.41 & 0.13 & 0.16 & 0.11 & 0.76 & 0.11 \\
\hline
\end{tabular}

Table 3. Trajectory number and Fine Mode AOD, Coarse Mode AOD \& Fine Mode Fraction mean concentration of each cluster of ICIPE Mbita, in MAM 2014.

\begin{tabular}{|c|c|c|c|c|c|c|c|}
\hline \multirow{2}{*}{\multicolumn{2}{|c|}{ Trajectory Number }} & \multicolumn{6}{|c|}{ Trajectory Number for wet season } \\
\hline & & \multicolumn{2}{|c|}{ Fine Mode } & \multicolumn{2}{|c|}{ Coarse Mode } & \multicolumn{2}{|c|}{$\begin{array}{l}\text { Fine Mode } \\
\text { Fraction }\end{array}$} \\
\hline Cluster & Number & Mean & S.D & Mean & S.D & Mean & S.D \\
\hline 1 & 14 & 0.14 & 0.03 & 0.10 & 0.04 & 0.62 & 0.06 \\
\hline 2 & 6 & 0.15 & 0.08 & 0.20 & 0.14 & 0.58 & 0.03 \\
\hline 3 & 1 & 0.00 & 0.00 & 0.08 & 0.00 & 0.52 & 0.00 \\
\hline 4 & 9 & 0.12 & 0.03 & 0.11 & 0.03 & 0.63 & 0.08 \\
\hline 5 & 2 & 0.00 & 0.00 & 0.00 & 0.00 & 0.69 & 0.10 \\
\hline
\end{tabular}

mean values, standard deviation, polluted trajectory number, polluted mean values and polluted standard deviation of each cluster.

The highest AOD concentrations at ICIPE Mbita occurred when the transport pathways were represented by clusters 1,2 and 4 . Among these three major pathways, cluster 1 is the most important because samples collected under its flow regime had the highest trajectories followed by cluster 4 . 
Table 4. Trajectory number and Fine Mode AOD, Coarse Mode AOD \& Fine Mode Fraction mean concentration of each cluster of ICIPE Mbita, in JJA 2014.

\begin{tabular}{cccccccc}
\hline \multirow{2}{*}{ Trajectory Number } & \multicolumn{3}{c}{ Trajectory Number for wet season } \\
\cline { 3 - 8 } & \multicolumn{2}{c}{ Fine Mode } & \multicolumn{2}{c}{ Coarse Mode } & \multicolumn{2}{c}{$\begin{array}{c}\text { Fine Mode } \\
\text { Fraction }\end{array}$} \\
\hline Cluster & Number & Mean & S.D & Mean & S.D & Mean & S.D \\
1 & 23 & 0.3 & 0.08 & 0.13 & 0.06 & 0.63 & 0.10 \\
2 & 6 & 0.24 & 0.04 & 0.13 & 0.04 & 0.66 & 0.03 \\
3 & 24 & 0.25 & 0.04 & 0.12 & 0.05 & 0.66 & 0.09 \\
4 & 6 & 0.26 & 0.00 & 0.17 & 0.02 & 0.60 & 0.05 \\
5 & 13 & 0.35 & 0.15 & 0.11 & 0.03 & 0.69 & 0.15 \\
\hline
\end{tabular}

Table 5. Trajectory number and Fine Mode AOD, Coarse Mode AOD \& Fine Mode Fraction mean concentration of each cluster of ICIPE Mbita, in MAM 2015.

\begin{tabular}{cccccccc}
\hline & & \multicolumn{3}{c}{ Trajectory Number for wet season } \\
\cline { 3 - 8 } Trajectory Number & \multicolumn{2}{c}{ Fine Mode } & \multicolumn{2}{c}{ Coarse Mode } & \multicolumn{2}{c}{$\begin{array}{c}\text { Fine Mode } \\
\text { Fraction }\end{array}$} \\
\hline Cluster & Number & Mean & S.D & Mean & S.D & Mean & S.D \\
1 & 15 & 0.11 & 0.00 & 0.09 & 0.04 & 0.58 & 0.09 \\
2 & 15 & 0.12 & 0.01 & 0.09 & 0.04 & 0.74 & 0.00 \\
3 & 1 & 0.00 & 0.00 & 0.00 & 0.00 & 0.55 & 0.00 \\
4 & 18 & 0.12 & 0.02 & 0.11 & 0.04 & 0.56 & 0.06 \\
5 & 2 & 0.12 & 0.00 & 0.09 & 0.00 & 0.75 & 0.10 \\
\hline
\end{tabular}

Table 6. Trajectory number and Fine Mode AOD, Coarse Mode AOD \& Fine Mode Fraction mean concentration of each cluster of ICIPE Mbita, in JJA 2015.

\begin{tabular}{|c|c|c|c|c|c|c|c|}
\hline \multirow{2}{*}{\multicolumn{2}{|c|}{ Trajectory Number }} & \multicolumn{6}{|c|}{ Trajectory Number for wet season } \\
\hline & & \multicolumn{2}{|c|}{ Fine Mode } & \multicolumn{2}{|c|}{ Coarse Mode } & \multicolumn{2}{|c|}{$\begin{array}{l}\text { Fine Mode } \\
\text { Fraction }\end{array}$} \\
\hline Cluster & Number & Mean & S.D & Mean & S.D & Mean & S.D \\
\hline 1 & 7 & 0.30 & 0.10 & 0.13 & 0.04 & 0.57 & 0.07 \\
\hline 2 & 18 & 0.22 & 0.02 & 0.14 & 0.07 & 0.58 & 0.06 \\
\hline 3 & 31 & 0.24 & 0.03 & 0.13 & 0.04 & 0.61 & 0.04 \\
\hline 4 & 15 & 0.24 & 0.04 & 0.15 & 0.05 & 0.59 & 0.08 \\
\hline 5 & 8 & 0.22 & 0.00 & 0.16 & 0.07 & 0.58 & 0.06 \\
\hline
\end{tabular}

The occurrence of high AOD concentrations in ICIPE Mbita in year 2014 can be linked to transport depicted by Clusters 1, 3 and 5 during MAM and clusters 1 and 5 during JJA because the total means AOD loadings associated with the Clusters mentioned above were the highest of all clusters, although some cluster appears to be shorter than the others Table 3 and Table 4 . The other clusters 
were considered less important as pathways for pollutants during these two seasons.

The air masses associated with Cluster 1 for 2013 MAM, 2014 MAM and 2015 MAM seasons Figure 5(d), Figure 5(e) and Figure 5(f), passed through the northern parts of North eastern province from Somalia, then through arid and semi-arid counties of Wajir, Isiolo, Samburu, Laikipia, then into Baringo, Nandi straight to ICIPE Mbita. While, air masses associated with cluster 3 emanated from Tanga Tanzania propagating through Mt. Kilimanjaro into Kenya Counties of Kajiado, Narok, Bomet, Nyamira and finally Homa Bay. Finally for the air masses of cluster 5 it passes through Jonglei and Eastern Equatorial from South Sudan into Northern part of Uganda bordering Kenya at Trans Nzoi and turns southward then south west to ICIPE_ Mbita.

It can be seen that from Table 5 and Table 6 that (2015) had the largest number of trajectories for both wet and dry season followed by Table 1 and Table 2 (2013) and Table 3 and Table 42014 respectively. These seasonal variations of trajectories match the decrease in occurrences for fine mode, coarse mode and fine mode fraction concentrations from 2013 to 2015. During MAM, the coarse mode is more dominant than the fine mode while in JJA fine mode is more dominant than the coarse mode for years 2013 and 2015. But during 2014, the fine mode fraction is more dominant during MAM season followed by coarse mode, fine mode respectively for both wet and dry seasons.

\section{Conclusions}

To identify the dominant transport routes at the ICIPE Mbita receptor site, a clustering analysis method was applied to study backward trajectories. It was evident that most trajectory pathways were obvious in JJA while there were a few of the same trajectory pathways found in MAM season.

In Kenya, the prevailing trade winds were mainly north-easterlies during MAM season and are very strong, which had a big influence on the transportation of trajectory pathways from Arabian Peninsula. While in JJA season, the winds were mainly south-easterlies which brought oceanic sea salt aerosols from Indian Ocean and Madagascar Island.

Through this research, it was also found out that there was a clear seasonal variation of transport pathways. The JJA season with the greatest number of polluted trajectories, had the highest value of AOD. However, in MAM season there was a fewer number of polluted trajectories, thus the value of AOD concentrations was low.

This trajectory statistical clustering method effectively enables us to identify the main trajectories with their source and sink points at ICIPE Mbita station. Even though this method is described as an objective way of clustering events, the results were quite good. In order for the future work to achieve better significant results, more numbers of years are required. Therefore, despite the relatively few years used for wet and dry seasons during 2013 to 2015, this analysis 
has been worthwhile.

\section{Acknowledgements}

First and foremost Misiani, Yin and Mwai wish to extend our sincere gratitude to the Principal Investigators and their staff in establishing and maintaining the AERONET site and for providing online data. Secondly we also owe our sincere thanks to the NOAA Air Resources Laboratory for computing back trajectories using the HYSPLIT model. Lastly Misiani and Mwai are also thankful to the People's Republic of China Government and Kenya Meteorological Department for granting us a fellowship and study leave, respectively, without which this work will not have been possible.

\section{References}

[1] Levy, R.C., Remer, L.A., Mattoo, S., Vermote, E.F. and Kaufman, Y.J. (2007) Second-Generation Operational Algorithm: Retrieval of Aerosol Properties over Land from Inversion of Moderate Resolution Imaging Spectroradiometer Spectral Reflectance. Journal of Geophysical Research Atmospheres, 112, 1-21.

[2] Stohl, A. (1998) Computation, Accuracy and Applications of Trajectories-A Review and Bibliography. Atmospheric Environment, 32, 947-966.

https://doi.org/10.1016/S1352-2310(97)00457-3

[3] Draxler, R. (1998) An Overview of the HYSPLIT Modeling System for Trajectory and Dispersion Applications.

[4] Draxler, R.R. and Hess, G.D. (1998) An Overview of the HYSPLIT_4 Modelling System for Trajectories. Australian Meteorological Magazine, 47, 295-308.

[5] Kenya National Bureau of Statistics (KNBS), ORC Macro (2010) Kenya Demographic and Health Survey 2008-09. Health (San Francisco), 1-314.

[6] Herrero, M., Ringler, C., Steeg, J. Van De, Koo, J. and Notenbaert, A. (2010) Climate Variability and Climate Change and Their Impacts on Kenya's Agricultural Sector. ILRI, Nairobi. Kenya, 1-56.

[7] Mugalavai, E.M., Kipkorir, E.C., Raes, D. and Rao, M.S. (2008) Analysis of Rainfall Onset, Cessation and Length of Growing Season for Western Kenya. Agricultural and Forest Meteorology, 148, 1123-1135.

https://doi.org/10.1016/j.agrformet.2008.02.013

[8] Sagero, P.O., Shisanya, C., Ongoma, V. and Shilenje, Z.W. (2016) Numerical Simulation of Rainfall and Temperature over Kenya Using Weather Research and Forecasting-Environmental Modelling System. International Scientific Journal Geographica Pannonica, 20, 51-61.

[9] Gatebe, C.K., King, M.D., Tsay, S.C., Ji, Q., Thomas Arnold, G. and Li, J.Y. (2001) Sensitivity of Off-Nadir Zenith Angles to Correlation between Visible and Near-Infrared Reflectance for Use in Remote Sensing of Aerosol over Land. IEEE Transactions on Geoscience and Remote Sensing, 39, 805-819. https://doi.org/10.1109/36.917901

[10] Makokha, J.W. and Muthama, J.N. (2017) Aerosol Optical Depth and Precipitation Rate Projections over East Africa Utilizing Self Organizing Map The International Journal of Science \& Technoledge, 5, 166-175.

[11] Boiyo, R., Kumar, K.R. and Zhao, T. (2017) Statistical Intercomparison and Valida- 
tion of Multisensory Aerosol Optical Depth Retrievals over Three AERONET Sites in Kenya, East Africa. Atmospheric Research, 197, 277-288.

https://doi.org/10.1016/j.atmosres.2017.07.012 